\title{
Morfologia e viabilidade de grãos de pólen de acessos silvestres de abacaxi
}

\author{
Morphology and viability of pollen grains from wild varieties of pineapple
}

\author{
Taliane Leila Soares ${ }^{\mathrm{I}}$ Everton Hilo de Souza ${ }^{\mathrm{I}}{ }^{*}$ Mônica Lanzoni Rossi ${ }^{\mathrm{II}}$ \\ Fernanda Vidigal Duarte Souza ${ }^{\text {III }}$
}

\section{RESUMO}

O objetivo do trabalho foi avaliar a viabilidade de grãos de pólen de acessos silvestres de abacaxi mediante a percentagem de germinação in vitro, crescimento do tubo polínico em duas temperaturas de incubação e uso de carmim acético. Além disso, o trabalho busca reconhecer os padrões da morfologia polínica de algumas variedades de abacaxi. Foram utilizadas amostras de pólen coletadas de seis acessos de abacaxi: Silvestre-25, I-26/803 (Ananas macrodontes), Igor (A. comosus var. erectifolius), Ananás Santo Amaro, FRF-22 e FRF-32 (A. comosus var. bracteatus). Os grãos de pólen foram inoculados em meio de cultura contendo $10 \%$ de sacarose, $0,01 \% \quad \mathrm{H}_{3} \mathrm{BO}_{3}, \quad 0,01 \% \quad \mathrm{KNO}_{3}, \quad 0,03 \% \quad \mathrm{Ca}\left(\mathrm{NO}_{3}\right)_{2} .4 \mathrm{H}_{2} \mathrm{O}$, solidificado com $1 \%$ de ágar e pH ajustado para 6,5. Foram testadas as temperaturas de incubação de $25^{\circ} \mathrm{C}$ e $30^{\circ} \mathrm{C} . \mathrm{A}$ viabilidade do pólen foi avaliada pela coloração com carmim acético a $2 \%$. Todas as variedades de A. comosus apresentaram grãos de pólen de tamanho médio, simetria radial, âmbito ovalado a esferoidal, 2-porados, subprolatos, exina eutectada, reticulada, heterobrocada, lumens variando de arredondados a poligonais, sem granulações, com exceção dos dois acessos de A. macrodontes que apresentaram tamanho grande. Melhores taxas de germinação foram obtidas para $\boldsymbol{A}$. macrodontes em comparação com o erectifolius e bracteatus. A maioria dos acessos apresentou viabilidade com carmim acético acima de $76 \%$.

Palavras-chave: Ananas, germinação in vitro, tubo polínico, carmim acético, plantas ornamentais, cultura in vitro.

\begin{abstract}
The aim of this research was to evaluate the pollen grains viability from accessions of wild pineapple using in vitro pollen germination and the growth of the polinic tube in two different temperatures and acetic carmine. In addition, the study aimed to recognize the pattern of pollen morphology of some pineapple varieties. Samples from six pineapple's accessions: Silvestre-25, I-26/803 (Ananas macrodontes), Igor (A. comosus var. erectifolius), Ananás Santo Amaro, FRF-22 and FRF-32 (A. comosus var. bracteatus) were used. The pollen grains were inoculated onto medium culture containing $10 \%$ of sucrose, $0.01 \% \mathrm{H}_{3} \mathrm{BO}_{3}, 0.01 \% \mathrm{KNO}_{3}, 0.03 \% \mathrm{Ca}\left(\mathrm{NO}_{3}\right)_{2} .4 \mathrm{H}_{2} \mathrm{O}$, solidified with $1 \%$ agar and $\mathrm{pH}$ adjusted to 6.5. Two incubation temperatures, $25^{\circ} \mathrm{C}$ e $30^{\circ} \mathrm{C}$ were evaluated. Pollen viability was evaluated by staining with $2 \%$ acetic carmine. All varieties of A. comosus showed pollen grains of medium size, radial symmetry, oval to spheroidal, ambit 2-porate, subprolate, exine eutectic, reticulate, heterobrochate, lumens ranging from polygonal to rounded, grain-free, except for two accessions of A. macrodontes that showed big size. The best germination rates were obtained for A. macrodontes when compared to erectifolius and bracteatus. The majority of accessions presented pollen viability higher than $76 \%$ using the acetic carmine technique.
\end{abstract}

Key words: Ananas, in vitro germination, pollen tube, acetic carmine, ornamental plants, in vitro culture.

IPrograma de Pós-graduação em Recursos Genéticos Vegetais, Universidade Federal do Recôncavo da Bahia (UFRB)/Embrapa Mandioca e Fruticultura, Cruz das Almas, BA, Brasil.

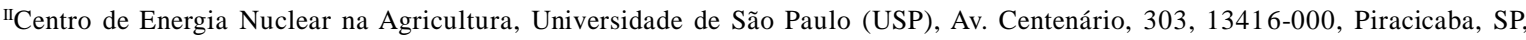
Brasil. E-mail: hilosouza@gmail.com. Autor para correspondência.

"IIEmbrapa Mandioca e Fruticultura, Cruz das Almas, BA, Brasil. 


\section{INTRODUÇÃO}

Os abacaxis silvestres, pertencentes ao gênero Ananas, têm potencial ornamental por sua beleza, rusticidade e originalidade. Recentemente, foi iniciado um programa para a geração de híbridos ornamentais com características apropriadas para uso como flor de corte, plantas de vaso ou para paisagismo de parques e jardins (SOUZA et al., 2009).

Os estudos referentes à morfologia, ultraestrutura polínica e germinação in vitro são de grande valia como subsídio aos programas de melhoramento genético, visando à obtenção de seleções potencialmente promissoras (CHAGAS et al., 2010). As hibridações para a obtenção de abacaxis ornamentais envolvem, em sua maioria, variedades silvestres pouco conhecidas e estudadas. A viabilidade do pólen é considerada uma medida de fertilidade masculina muito empregada no monitoramento de pólen armazenado, de modo a garantir a fecundação e tornar possíveis cruzamentos entre genótipos de potencial econômico que apresentam floração em épocas distintas. A determinação da viabilidade do pólen pode ser feita através de métodos diretos, tais como a indução da germinação in vitro (PIO et al., 2007)

O sucesso da germinação in vitro depende de vários fatores como espécie vegetal, estado nutricional das plantas, época do ano e horário de coleta, fotoperíodo, temperatura, método de coleta, período de incubação e presença de micro e macronutrientes no meio de cultura (SOARES et al. 2008), além de ajustes da composição dos meios de cultura para cada espécie (CHAGAS et al., 2010; SINIMBU NETO et al., 2011). Apesar da extensa literatura que trata da morfologia polínica e germinação de pólen in vitro de muitas espécies agrícolas, ornamentais e florestais, até o momento não há relatos sobre estudos com grãos de pólen de abacaxi, especialmente trabalhos envolvendo variedades silvestres, que são a base para o melhoramento genético de abacaxis ornamentais e que nem sempre apresentam florescimento sincrônico, demandando o armazenamento de pólen viável.

Com vistas a obter subsídios para programas de melhoramento do abacaxizeiro ornamental e identificar possíveis parentais para futuras hibridações, este trabalho teve como objetivo avaliar a fertilidade de variedades silvestres de abacaxi por meio da germinação in vitro de grãos de pólen e do crescimento do tubo polínico em diferentes temperaturas de incubação, bem como examinar o uso de carmim acético como teste de viabilidade. Além disso, o trabalho busca reconhecer os padrões da morfologia polínica de algumas variedades de abacaxi.

\section{MATERIAL E MÉTODOS}

Foram utilizados grãos de pólen oriundos de flores coletadas na antese (aprox. 7:30h) do Banco Ativo de Germoplasma da Embrapa Mandioca e Fruticultura, Cruz das Almas, Bahia, Brasil, de seis acessos de abacaxis ornamentais: Silvestre-25 e I-26/ 803 (Ananas macrodontes), Igor (A. comosus var erectifolius), Ananás Santo Amaro, FRF-22 e FRF-32 (A. comosus var bracteatus) (Figura 1A-F).

As medidas dos grãos de pólen foram realizadas através de acetólise lática fraca (ACLAC 40), conforme metodologia descrita por RAYNAL \& RAYNAL (1979), na qual foi medido aleatoriamente o diâmetro polar e equatorial $(\mu \mathrm{m})$ de 30 grãos de pólen.

Para caracterização morfológica, os grãos de pólen foram fixados em solução de Karnovsky modificada (glutaraldeído (2\%), paraformaldeído (2\%), $\mathrm{CaCl}_{2}$ 0,001M, tampão cacodilato de sódio (0,05M), em $\mathrm{pH} 7,2$ ) por 48 horas, desidratados em série etílica crescente. Em seguida, o material passou por secagem ao ponto crítico, utilizando CO líquido (Blazers CPD/ 030). As amostras secas foram montadas sobre suportes metálicos (stubs) e metalizadas com ouro durante 180 segundos. As imagens foram obtidas no microscópio eletrônico de varredura de pressão variável LEO 435 VP do Núcleo de Apoio à Pesquisa em Microscopia Eletrônica Aplicada a Agricultura da Escola Superior de Agricultura 'Luiz de Queiroz', Universidade de São Paulo (NAP/MEPA - ESALQ/USP).

As amostras processadas para microscopia eletrônica de transmissão (MET) foram fixadas na mesma solução de Karnovsky modificada por 24 horas. Posteriormente, foram lavadas em tampão cacodilato de sódio $(0,1 \mathrm{M})$, seguida de pós-fixação em tetróxido de ósmio ( $1 \%)$, solução salina $(0,9 \%)$ e pré coloração em acetato de uranila (2,5\%). Em seguida, as amostras passaram por desidratação em série crescente de acetona. A infiltração foi gradual em resina Spurr. O material foi emblocado em resina pura por 48 horas, a $70^{\circ} \mathrm{C}$ e os blocos seccionados em ultramicrótomo Sorval Porter Blum MT2. As secções ultrafinas obtidas foram depositadas sobre grades de cobre previamente recobertas com formvar, contrastadas com acetato de uranila $(2,5 \%)$ e citrato de chumbo, segundo REYNOLDS (1963). As imagens foram obtidas no microscópio eletrônico de transmissão Zeiss EM900 no NAP/MEPA - ESALQ/USP.

Para a germinação in vitro, os grãos de pólen sem nenhum processo de assepsia foram inoculados em 35mL do meio de cultura de BREWBAKER \& KWACK (1963) contendo 0,03\% de nitrato de cálcio, $0,01 \%$ de nitrato de potássio, $0,01 \%$ de ácido bórico 


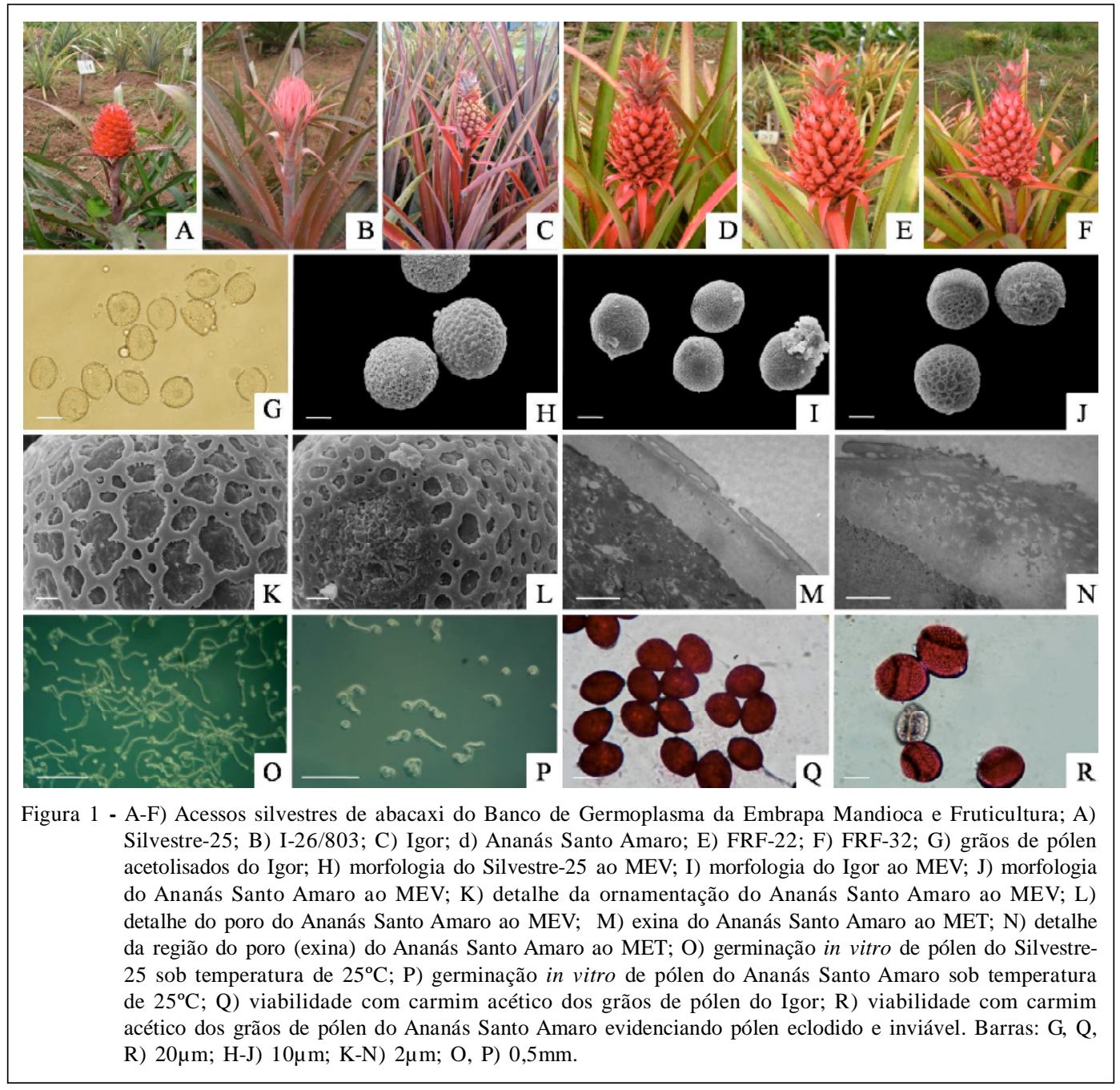

suplementado com $10 \%$ de sacarose, solidificado com $1 \%$ de ágar $\left(\right.$ Merck $\left.^{\circledR}\right)$ e pH ajustado para 6,5 antes da autoclavagem. Com auxílio de um pincel, o pólen foi distribuído em placas de Petri descartáveis (90x16mm), vedadas com parafilme e mantidas em câmara climatizada, em duas condições controladas de temperatura $\left(25^{\circ} \mathrm{C} \mathrm{e} 30^{\circ} \mathrm{C}\right)$ até a realização da contagem dos grãos de pólen germinados e medição do tubo polínico, 24 horas após a inoculação em meio de cultura.

O delineamento experimental utilizado para a germinação do pólen foi inteiramente casualizado em esquema fatorial $6 \times 2$ (acessos $\mathrm{x}$ temperatura de incubações), com 12 repetições, sendo cada repetição representada por uma placa de Petri. Para a percentagem de germinação, foram contabilizados todos os grãos de pólen da placa, enquanto para o comprimento do tubo polínico foram mensurados aleatoriamente cinco tubos em cada placa de Petri, totalizando 60 tubos polínicos de cada genótipo estudado. Foram considerados germinados os grãos de pólen que possuíam tubo polínico com tamanho igual ou superior ao diâmetro do próprio pólen.

Para análise da viabilidade, uma amostra de pólen retirada de três anteras oriundas de flores coletadas da mesma bráctea foi distribuída sobre uma lâmina de vidro, adicionando carmim acético a $2 \%$, fechando-se o conjunto com uma lamínula. A observação e registro de grãos de pólen deram-se logo após a preparação das lâminas. A fim de se obter uma amostragem ao acaso dos grãos de pólen corados foi utilizado o método de varredura da lâmina em um microscópio óptico com lente objetiva de 10x, sendo contabilizados 100 grãos de pólen/lâmina/genótipo com três repetições cada, perfazendo um total de 300 grãos de pólen. Estimou-se o percentual de fertilidade do pólen mediante a proporção entre o número de grãos de pólen corados (viáveis) e não corados ou com citoplasma retraído (não viáveis). Os dados de 
percentagem de germinação foram transformados para $\operatorname{arc} \operatorname{sen}(\sqrt{x / 100})$ antes da análise estatística. Para comparação das médias, os dados foram submetidos à análise de variância, utilizando-se teste de Scott-Knott, ao nível de $5 \%$ de probabilidade, através do programa SAS (2004).

\section{RESULTADOS E DISCUSSÃO}

Os dados morfométricos empregados na determinação do formato e tamanho dos grãos de pólen estão disponíveis na tabela 1. Todos os acessos apresentaram grãos de pólen de tamanho médio, simetria radial, âmbito ovalado a esferoidal, 2-porados, subprolatos, exina eutectada, reticulada, heterobrocada, lumens variando de arredondados a poligonais, sem granulações, com exceção dos acessos de $\boldsymbol{A}$. macrodontes que apresentaram tamanho grande (Figura 1G-N), conforme nomenclatura empregada por PUNT et al. (2007).

O emprego de caracteres morfopolínicos para estudos taxonômicos é uma alternativa ao uso de outras características, como cor de folhas e flores e tamanho de estruturas, que estão mais sujeitas a alterações quando comparadas às características dos grãos de pólen, consideradas mais conservadas (BENZING 2006).

Entre os acessos estudados, houve a formação de diferentes agrupamentos pelo teste de Scott-Knott em nível de 5\% de probabilidade, em relação às temperaturas testadas, tanto para percentagem de germinação, como para o comprimento do tubo polínico, ocorrendo também a interação entre esses dois fatores (Tabela 2).

As mais altas percentagens de germinação e comprimento de tubo polínico foram obtidos para os acessos Silvestre-25 e I-26/803 (ambos pertencentes a uma mesma espécie, A. macrodontes) (Tabela 2, Figura 10). Por outro lado, as mais baixas percentagens de germinação foram observadas no acesso Ananás Santo
Amaro, pertencente à variedade bracteatus, em ambas as temperaturas de incubação (Figura 1P), ainda que, mediante coloração com carmim acético, tenham apresentado alta viabilidade 76\% (Tabela 2). Os outros dois genótipos pertencentes a essa mesma variedade (FRF-22 e FRF-32) apresentaram percentagens de germinação igualmente baixas, inferiores a 48,38\% nas duas temperaturas. Essa variedade (A. comosus var. bracteatus) é muito importante para o melhoramento de ornamentais devido à exuberância de seus frutos de coloração rosa intenso e brácteas grandes que chegam a cobrir os frutilhos, conferindo-lhes uma beleza característica. Os resultados obtidos com as medidas de comprimento do tubo polínico (Tabela 2) acompanham os resultados de germinação, mostrando valores bem menores que os observados nos outros acessos estudados.

Essa baixa taxa de germinação e o pouco crescimento do tubo polínico podem ser atribuídos a diversos fatores, como o próprio meio de cultura ou a uma excessiva hidratação apresentada pelos grãos de pólen. PIO et al. (2004) afirmaram que, além da composição do meio, a temperatura e a alta umidade podem ocasionar aumento na pressão osmótica e baixa resistência na parede celular, causando assim o rompimento ou eclosão dos grãos de pólen, impedindoos de germinar.

Temperaturas de incubação em torno de $25^{\circ} \mathrm{C}$ são citadas em estudos de germinação in vitro de pólen de diversas espécies, a exemplo de FRANZON et al. (2006) que usaram $25^{\circ} \mathrm{C}$ para grãos pólen de guabirobeira, a mesma empregada por NUNES et al. (2001) e FRANZON et al. (2007) para estudos com macieira e pitangueira, respectivamente. Para Citrus, a temperatura ideal para a germinação dos grãos de pólen foi de $25^{\circ} \mathrm{C}$, similar a de muitas espécies citadas na literatura, em que os melhores índices de germinação ocorrem no intervalo de $20^{\circ} \mathrm{Ca} 30^{\circ} \mathrm{C}$ (PIO et al., 2004). A constatação de uma temperatura ideal na germinação in vitro pode ter uma implicação prática importante,

Tabela 1 - Medidas de grãos de pólen acetolisados e espessura da exina através da microscopia eletrônica de transmissão de acessos de abacaxizeiros ornamentais. Embrapa Mandioca e Fruticultura, Cruz das Almas, Bahia, 2010.

\begin{tabular}{lccc}
\hline & & & \\
Espécie (Espécie) & Diâmetro polar $(\mu \mathrm{m})$ & Diâmetro equatorial $(\mu \mathrm{m})$ & Exina $(\mu \mathrm{m})$ \\
\hline Silvestre-25 (A. macrodontes) & $51,12 \pm 2,13$ & $45,29 \pm 1,98$ & $3,17 \pm 0,14$ \\
I-26/803 (A. macrodontes) & $53,06 \pm 2,53$ & $46,60 \pm 2,06$ & $3,08 \pm 0,11$ \\
Igor (A. comosus var. erectifolius) & $44,70 \pm 3,03$ & $37,64 \pm 1,92$ & $2,14 \pm 0,16$ \\
Ananás Santo Amaro (A. comosus var. bracteatus) & $49,30 \pm 3,01$ & $41,45 \pm 2,01$ & $2,63 \pm 0,10$ \\
FRF-22 (A. comosus var. bracteatus) & $47,80 \pm 3,41$ & $39,23 \pm 2,24$ & $2,70 \pm 0,12$ \\
FRF-32 (A. comosus var. bracteatus) & $45,18 \pm 2,93$ & $38,18 \pm 2,16$ & $2,77 \pm 0,13$ \\
\hline
\end{tabular}


Tabela 2 - Germinação, comprimento do tubo polínico e viabilidade dos grãos de pólen de diferentes acessos de abacaxizeiros ornamentais. Embrapa Mandioca e Fruticultura, Cruz das Almas, Bahia, 2010.

\begin{tabular}{|c|c|c|c|c|c|}
\hline \multirow{2}{*}{ Acesso (Espécie) } & \multicolumn{2}{|c|}{ Germinação de pólen (\%) } & \multicolumn{2}{|c|}{ Comprimento tubo polínico(mm) } & \multirow{2}{*}{$\begin{array}{l}\text { Viabilidade com } \\
\text { carmim }(\%)\end{array}$} \\
\hline & $25^{\circ} \mathrm{C}$ & $30^{\circ} \mathrm{C}$ & $25^{\circ} \mathrm{C}$ & $30^{\circ} \mathrm{C}$ & \\
\hline $\begin{array}{l}\text { Silvestre- } 25 \\
\text { (A. macrodontes) }\end{array}$ & $82,07 \mathrm{aA}$ & $56,80 \mathrm{aB}$ & $1,29 \pm 0,42 \mathrm{bA}$ & $0,46 \pm 0,12 \mathrm{cB}$ & $100 \mathrm{a}$ \\
\hline $\begin{array}{l}\mathrm{I}-26 / 803 \\
\text { (A. macrodontes) }\end{array}$ & $70,50 \mathrm{bA}$ & $52,10 \mathrm{aB}$ & $1,54 \pm 0,57 \mathrm{aA}$ & $0,78 \pm 0,12 \mathrm{aB}$ & $85 \mathrm{ab}$ \\
\hline $\begin{array}{l}\text { Igor } \\
\text { (A. comosus var. erectifolius) }\end{array}$ & $59,50 \mathrm{bA}$ & $49,63 \mathrm{aA}$ & $0,30 \pm 0,05 \mathrm{~dB}$ & $0,58 \pm 0,14 \mathrm{bA}$ & $100 \mathrm{a}$ \\
\hline $\begin{array}{l}\text { Ananás Santo Amaro } \\
\text { (A. comosus var. bracteatus) }\end{array}$ & $23,50 \mathrm{dA}$ & $30,00 \mathrm{bA}$ & $0,23 \pm 0,05 \mathrm{dA}$ & $0,24 \pm 0,05 \mathrm{dA}$ & $76 \mathrm{~b}$ \\
\hline $\begin{array}{l}\text { FRF- } 22 \\
\text { (A. comosus var. bracteatus) }\end{array}$ & $42,73 \mathrm{cA}$ & $48,38 \mathrm{aA}$ & $0,50 \pm 0,19 \mathrm{cA}$ & $0,39 \pm 0,12 \mathrm{cB}$ & $90 \mathrm{a}$ \\
\hline $\begin{array}{l}\text { FRF-32 } \\
\text { (A. comosus var. bracteatus) }\end{array}$ & $31,50 \mathrm{dA}$ & $39,50 \mathrm{bA}$ & $*$ & $0,37 \pm 0,11 \mathrm{c}$ & $88 \mathrm{a}$ \\
\hline $\mathrm{CV}(\%)$ & \multicolumn{2}{|c|}{18,60} & \multicolumn{2}{|c|}{39,27} & 14,32 \\
\hline
\end{tabular}

Médias seguidas pela mesma letra minúscula na coluna fazem parte do mesmo agrupamento pelo teste de Scott \& Knott a 5\% de probabilidade e maiúscula na linha não diferem entre si pelo teste de Tukey a 5\% de probabilidade.

* Tratamento acometido por contaminação fúngica.

uma vez que pode direcionar o melhor horário para a realização dos cruzamentos. Os resultados do presente estudo sugerem que a temperatura de $25^{\circ} \mathrm{C}$ seja mais adequada para o $\boldsymbol{A}$. macrodontes, e a de $30^{\circ} \mathrm{C}$ para $\boldsymbol{A}$. comosus var. bracteatus, embora as diferenças estatísticas não tenham sido significativas.

Os resultados obtidos com carmim acético, em sua maioria, não corresponderam ao que foi obtido com a germinação in vitro, apresentando valores acima de $76 \%$ de viabilidade para todos os acessos estudados (Tabela 2 e Figura 1Q). Na figura 1R, é possível observar grãos de pólen viáveis e inviáveis a partir da técnica de carmim acético. De um modo geral, os grãos de pólen viáveis apresentaram-se mais desenvolvidos, mais circulares e coraram-se melhor na presença do carmim acético, enquanto os inviáveis apresentaram-se mal formados, elípticos e pouco corados pelo carmim.

Para EINHARDT et al. (2006), a coloração, embora seja um procedimento simples e barato, poderá superestimar os valores de viabilidade. Além disso, a germinação in vitro, embora forneça um sistema experimental controlado, não reproduz completamente o crescimento do tubo polínico in vivo, podendo ocorrer interações entre a composição de meio de cultura e os diferentes materiais vegetais.

Entretanto, é possível concordar com SOARES et al. (2008), que se refere à técnica de germinação in vitro como aquela que apresenta resultados mais próximos aos que, provavelmente, ocorrem in vivo e, por isso, a importância de tê-la bem ajustada para cada espécie em estudo. É interessante salientar que o pólen dos abacaxizeiros ornamentais foi coletado de inflorescências no mesmo estádio fisiológico, ou seja, na antese e no mesmo horário. Para FRANZON \& RASEIRA (2006), é fundamental utilizar em programas de melhoramento o pólen em estádio adequado de maturação, para que mantenha a viabilidade e capacidade de germinação quando for realizada a hibridação.

\section{CONCLUSÃO}

As variedades de $\boldsymbol{A}$. comosus apresentaram semelhança quanto à morfologia e ultraestrutura polínica, diferenciando apenas da espécie $\boldsymbol{A}$. macrodontes em tamanho do pólen. Por outro lado, a temperatura de $25^{\circ} \mathrm{C}$ foi a mais adequada para o $\boldsymbol{A}$. macrodontes, enquanto que para as demais variedades não houve diferença entre as temperaturas. Quanto às taxas de germinação, foram mais elevadas quando aferidas pela coloração com carmim acético em comparação com a germinação in vitro e foram maiores em $\boldsymbol{A}$. macrodontes do que nas variedades erectifolius e bracteatus.

\section{AGRADECIMENTOS}

Ao Banco do Nordeste S/A, pelo apoio financeiro ao projeto e ao Núcleo de Apoio à Pesquisa em Microscopia Eletrônica Aplicada a Agricultura da Escola Superior de Agricultura 'Luiz de Queiroz", Universidade de São Paulo (NAP/ MEPA/ESALQ/USP).

Ciência Rural, v.41, n.10, out, 2011. 


\section{REFERÊNCIAS}

BENZING, D.H. Bromeliaceae: profile an adaptive radiation. Cambridge: Cambridge University, 2006. 690p.

BREWBAKER, J.L.; KWACK, B.H. The essential role of calcium ion in pollen germination and pollen tube gowth. American Journal of Botany, v.50, n.9, p.859-865. 1963. Disponível em: < http://www.jstor.org/stable/2439772?seq=1>. Acesso em: 8 ago. 2011.

CHAGAS, E.A. et al. Composição de meio de cultura e condições ambientais para germinação de grãos de pólen de porta-enxertos de pereira. Ciência Rural, v.40, n.2, p.231-236, 2010. Disponível em: 〈http://www.scielo.br/pdf/cr/v40n2/a485cr2215.pdf〉. Acesso em: 27 jul. 2011. doi: 10.1590/S0103-84782010000200002.

EINHARDT, P.M. et al. Comparação entre métodos para testar a viabilidade de pólen de pessegueiro. Revista Brasileira de Fruticultura, v.28, n.1, p.5-7, 2006. Disponível em: $<$ http:/ /www.scielo.br/pdf/rbf/v28n1/29678.pdf >. Acesso em: 18 jun. 2011. doi: $10.1590 / \mathrm{S} 0100-29452006000100004$.

FRANZON, R.C. et al. Testes de germinação in vitro e armazenamento de pólen de pitangueira (Eugenia uniflora L.). Acta Scientiarum Agronomy, v.29, n.2, p.251-255, 2007. Disponível em: <http://periodicos.uem.br/ojs/index.php/ ActaSciAgronarticle /view/267/118>. Acesso em: 18 jun. 2011. doi: $10.4025 /$ actasciagron.v29i2.267.

FRANZON, R.C. et al. Germinação in vitro de pólen de guabirobeira (Campomanesia xanthocarpa Berg). Revista Ceres, v.53, n.305, p.129-134. 2006. Disponível em: <http:/ /www.scielo.br/pdf/cr/v39n5/a188cr1310.pdf >. Acesso em: 27 jul. 2011

FRANZON, R.C.; RASEIRA, M.C.B. Germinação in vitro e armazenamento do pólen de Eugenia involucrata DC (Myrtaceae). Revista Brasileira de Fruticultura, v.28, n.1, p.18-20, 2006. Disponível em: <http://www.scielo.br/pdf/rbf/ v28n1/29682.pdf>. Acesso em: 18 jun. 2011. doi:10.1590/ S0100-29452006000100008.

NUNES, J.C,O. et al. Germinação de pólen in vitro e receptividade do estigma em macieira cvs. 'Fuji' e 'Golden Delicious'. Revista Brasileira de Fruticultura, v.23, n.1, p.35-39, 2001.
PIO, L.A.S. et al. Receptiveness of the stigma and in vitro germination of orange pollen, submitted to different temperatures. Ciência e Agrotecnologia, v.5, n.5, p.10871091, 2004. Disponível em: <http://www.scielo.br/pdf/cagro/ v28n5/v28n5a16.pdf>. Acesso em: 20 jun. 2011. doi: 10.1590/ S1413-70542004000500016.

PIO, L.A.S. et al. Viabilidade do pólen de laranjas doces em diferentes condições de armazenamento. Ciência e Agrotecnologia, v.31, n.1, p.147-153, 2007. Disponível em: <http://www.scielo.br/pdf/cagro/v31n1/v31n1a22.pdf>. Acesso em: 20 jun. 2011. doi: 10.1590/S1413-70542007000100022.

PUNT, W. et al. Glossary of pollen and spore terminology. Review of Palaeobotany and Palynology, v.143, p.1-81, 2007. Disponível em: <http://www.sciencedirect.com/science/ article/pii/S0034666706001291>. Acesso em: 8 ago. 2011. doi:10.1016/ j.revpalbo.2006.06.008.

RAYNAL, A.; RAYNAL, J. Une technique de préparation des grains de pollen fragiles. Adansonia, v.2, n.11, p.77-79, 1979.

REYNOLDS, E.S. The use of lead citrate at high $\mathrm{pH}$ as an electron-opaque stain in electron microscopy. Journal of Cell Biology, v.17, p.208-212, 1963.

SAS Institute Inc. Sas/Stat user's guide: statistics, Version 9.1.3ed. Cary, 2004. 1037p.

SINIMBU NETO, F.A. et al. Viabilidade "in vitro" de grãos de pólen de bacurizeiro - Clusiaceae. Revista Brasileira de Fruticultura, ahead of print, 03-Jun-2011. 2011. Disponível em: <http://www.scielo.br/pdf/rbf/2011 nahead/ AOP\%2004711.pdf>. Acesso em: 27 jul. 2011. doi: 10.1590/ S0100-29452011005000062.

SOARES, T.L. et al. In vitro germination and viability of pollen grains of banana diploids. Crop Breeding and Applied Biotechnology, v.8, p.111-118. 2008. Disponível em: <http:/ /www.sbmp.org.br/cbab/siscbab/uploads/bd6b9df0-14d5c291.pdf>. Acesso em: 18 jun. 2011.

SOUZA, F.V.D. et al. Evaluation of F1 hybrids between Ananas comosus var. ananassoides and Ananas comosus var. erectifolius. Acta Horticulturae, v.822, p.79-84. 2009. Disponível em: <http://www.actahort.org/books/822/822_8.htm>. Acesso em: 20 jun. 2011. 